\title{
LARGE ANIMAL MODEL FOR OSTEOPOROSIS IN HUMANS: THE EWE
}

\author{
Ralf Oheim ${ }^{1}$, Michael Amling ${ }^{1 *}$, Anita Ignatius ${ }^{2}$ and Pia Pogoda ${ }^{3}$
}

\begin{abstract}
${ }^{1}$ Department of Osteology and Biomechanics, University Medical Centre Hamburg-Eppendorf, Hamburg, Germany
${ }^{2}$ Institute of Orthopaedic Research and Biomechanics, Centre of Musculoskeletal Research, University of Ulm, Ulm, Germany

${ }^{3}$ Department of Trauma, Hand and Reconstructive Surgery, University Medical Centre Hamburg-Eppendorf, Hamburg, Germany
\end{abstract}

\begin{abstract}
Osteoporosis is a chronic systemic disease characterised by bone loss and microarchitectural deterioration. Since the underlying regulatory mechanisms are still not fully understood and treatment options are not satisfactorily resolved, massive efforts are underway to further investigate this critical illness. Large animal models are stipulated, e.g. by the Food and Drug Administration, for preclinical prevention and intervention studies related to osteoporosis research; in this context, the ewe has already proven its value for orthopaedic research. Although oestrogen deficiency doubtless influences bone metabolism in sheep, the ovariectomised ewe seems unsuitable as a model for postmenopausal osteoporosis and bone loss induction due to its unreliable impact on bone mass and structure. In contrast, glucocorticoid treatment has a major impact on bone turnover and leads to bone conditions comparable to those found in steroid-treated humans. However, adverse side effects can be dramatic resulting in unacceptable discomfort and illness of the experimental animals. Further improvements are therefore essential to judge this model as ethically appropriate. Additionally, models for osteoporosis induced by surgical interventions of central regulatory mechanisms seem to be attractive, as remarkable bone loss is induced by only one surgical procedure without any further treatment. Taken together, different ewe models for osteoporosis have been successfully established and are invaluable for orthopaedic research. However, the search for a 'perfect' large remodelling animal model - in terms of mimicking the human disease and compatibility of bone loss, and without ethical concerns - is still on-going.
\end{abstract}

Keywords: Large animal models; sheep; osteoporosis; bone; orthopaedics.

*Address for correspondence:

Michael Amling, MD

Department of Osteology and Biomechanics

University Medical Centre Hamburg-Eppendorf

Martinistraße 52

20246 Hamburg, Germany

Telephone Number: $++49-40-7410-56083$

FAX Number: ++49-40-7410-58010

E-mail: amling@uke.uni-hamburg.de

\section{Introduction}

Osteoporosis is a chronic systemic disease characterised by bone loss and by microarchitectural deterioration, leading to skeletal fragility associated with an increased risk of fractures. Whereas secondary osteoporosis is caused by recognisable factors - such as glucocorticoid therapy, gastrointestinal disorders or immobilisation the underlying causes of the far more common primary osteoporosis ( $90 \%)$ remain unclear (Kalu, 1999). This socially and economically dramatic health problem in Western society is going to be even more critical as a result of demographic changes (Melton, 2003; Riggs and Melton, 1986). For example, Chrischilles et al. (1991) calculated that every second white woman above 50 years of age would suffer from an osteoporotic fracture during her remaining lifetime, followed by disability, increased mortality and financial burden. Not only women, but also every third man will suffer from osteoporotic fractures during their lifetime (Ross, 1996). Since the underlying regulatory mechanisms of the characteristic bone mass and structural impairments are still not fully understood and treatment options - surgical as well as non-surgical - are still not satisfactorily resolved, massive efforts are underway to further investigate this critical illness.

In vitro analyses of different bone cell types are helpful in answering important questions at the molecular biological level; however, they are not able to address the important interactions of various organ systems, or structural and biomechanical issues. Although animal models are doubtless essential at this time, "if a disease or condition is not fully understood, how can one design a good animal model of the disease? This is the animal model paradox" (Kalu, 1999). Therefore, even animal models representing only some aspects of the respective human condition may be useful (Hazzard et al., 1992). Indeed, each animal model can - by its nature - only mimic certain aspects of human diseases.

Small animal models - especially rodents - are attractive for studying bone metabolism and disorders using specific modifications of their genetic background. Moreover, in contrast to large animal models, these experiments are less costly and time-consuming. Nevertheless, there are important issues that cannot be fully addressed in small animal models, such as metaphyseal fracture healing or advancement of orthopaedic implants. Furthermore, the American Food and Drug Administration (FDA) recommends ovariectomised animals as the preferred model for bone loss research (Thompson et al., 1995). 


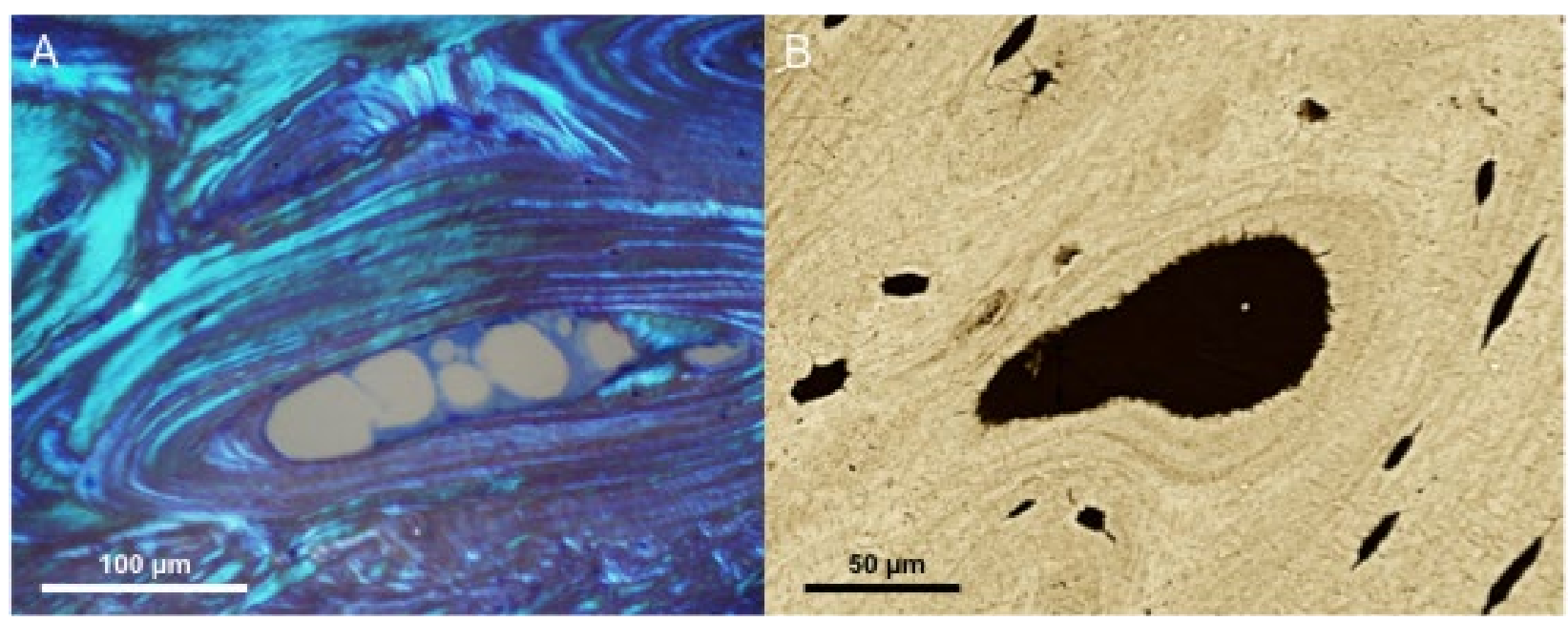

Fig. 1. Older sheep show lamellar bone structure with well-developed Haversian systems and they remodel their skeleton, which makes them suitable as large animal models for human bone diseases. (A) Histological image of aged ewe's iliac crest under polarised light. (B) Electron microscopic image of femoral cortical bone of aged ewe.

Following the guidelines of the World Health Organisation (WHO), drug effects must be demonstrated in appropriate animal models for osteoporosis (Bonjour et al., 1999).

Among other large animal models - e.g. dogs, pigs, goats and non-human primates - sheep have proven invaluable in orthopaedic research (Reinwald and Burr, 2008; Pearce et al., 2007). Due to their size, large animals - and sheep in particular - are convenient for studying orthopaedic implants comparable to those used in humans (Rocca et al., 2002; Borsari et al., 2007). In addition, their size allows investigation of structure, fractures and fracture healing of the metaphyseal bone - the 'hot-spot' area of osteoporotic fractures (Riggs and Melton, 1986). Furthermore, repeated histomorphometric analyses using substantial blood and urine samples, as well as iliac crest biopsies, can be performed (Turner, 2002).

With this review article, we aimed at discussing the pros and cons of the ewe as a model for human bone loss/osteoporosis. Thereby we paid particular attention to differences between various models in terms of bone loss, handling, costs and last but not least animal welfare. Furthermore, the field has changed substantially since the last reviews were published. The introduction of centrally controlled bone loss models is the most obvious novelty in this field. Additionally, ethical concerns changed during the past decades, which is why there is a need for a much more critical view on all animal models, particularly on glucocorticoid models.

\section{Characteristics}

Female sheep (ewes) are attractive to work with because of their "docile compliant nature" (Turner, 2002). They have simple husbandry needs, costs of acquisition and maintenance are low, and aged animals ( $>6$ years) are available in large numbers (Newman et al., 1995; Kalu, 1999). Last, but not least, ethical and societal implications are generally not sensitive compared to other large animal models (Reinwald and Burr, 2008). Many different sheep breeds have been used for scientific research such as Corriedale (Pogoda et al., 2006; Beil et al., 2012), Merino (Augat et al., 2003; Ding et al., 2010), Dorset (Newton et al., 2004), Swiss White Alpine (Sigrist et al., 2007; Egermann et al., 2011) and Swiss Mountain sheep (Lill et al., 2002), whereas some studies were designed using mixed breeds (Kennedy et al., 2008; Holland et al., 2011). Since the characteristics of different sheep breeds may vary significantly - according to their adaptation to specific environmental conditions - it is not recommended to use mixed breeds. For the same reason experimental results may vary considerably between different breeds.

\section{Oestrous cycles}

Spontaneous menopause is typically found only in humans, Old World monkeys and great apes; most other mammalian species experience lifelong oestrous cycles (Sone et al., 2007; Reinwald and Burr, 2008). Therefore, accelerated bone-loss caused by oestrogen deficiency cannot be observed naturally in non-human mammals (Turner, 2002). Sheep, in particular, are predominantly polyoestrous/ seasonal short day breeders with high oestrogen levels in autumn and winter and low oestrogen levels in spring and summer. However, some breeds (e.g. Merinos) cycle almost year-round (O'Connell, 1999), which might be beneficial in minimising seasonal influences on bone mass. The importance of oestrogen and its influence on bone turnover is in every case markedly less pronounced in sheep in comparison to woman. Although oestrogen-dependent reproductive cycles are found in woman and ewe, cycle characteristics vary significantly between both species (e.g. cycle length (days): woman 28 vs. ewe 17; approximate oestrogen peak (pg/mL): woman 300-600 vs. ewe 8-10) (Goodman, 1994; Reinwald and Burr, 2008). Moreover, animals with rare cycles and/or low oestrogen levels barely show significant effects on bone mass or structure after ovariectomy (see below). 


\section{Bone metabolism and structure}

In contrast to small animals - such as rodents - bone structure of sheep is comparable to those of humans. In particular, trabecular and cortical bone is found in ewes with Haversian systems, as well as bone remodelling performed by bone multicellular units (BMUs) (Arens et al., 2007; Reinwald and Burr, 2008; Kalu, 1999) (Fig. 1). As in other rapidly growing large animals, the cortical bone of young sheep is plexiform (Hornby et al., 1995; Newman et al., 1995; Turner, 2002). It is characterised by a combination of woven and lamellar bone and allows the animals to grow rapidly under optimal mechanical properties (Turner, 2002). Although there are functional similarities between plexiform and lamellar bone, deposition and organisation of plexiform bone shows distinct differences (Newman et al., 1995). Older sheep ( 1 year) show bone remodelling with well-developed Haversian systems (Hornby et al., 1995; Newman et al., 1995; Mori et al., 2005; Kalu, 1999). However, remodelling of all primary osteonal bone is not observed until 7-9 years of age (Turner, 2002; Pearce et al., 2007; Reinwald and Burr, 2008).

Bone formation in mammalians is characterised by rapid deposition of less oriented primary bone, followed by a slower formation of formed - lamellar - secondary bone (Currey, 2002). Due to recent findings, the same mechanisms seem to be relevant in fracture healing (Shapiro, 2008; Liu et al., 2010). In rapidly growing animals, such as sheep, these mechanisms are found to be particularly evident (Mori et al., 2007). That is why the sheep is indeed one of the favourite models for studying fracture healing in vivo (Claes et al., 1998; Manjubala et al., 2009; Checa et al., 2011; Kerschnitzki et al., 2011; Witt et al., 2011).

The relevance of biochemical bone markers such as alkaline phosphatase, osteocalcin or crosslinks for monitoring bone turnover in mammalians is well known and could also be demonstrated in sheep (Arens et al., 2007; Ding et al., 2010). Comparison of bone turnover parameters reflects $\geq$ six-fold higher remodelling speed in sheep compared to humans (Corlett et al., 1990), thus one year of bone remodelling in sheep probably corresponds to 5-10 years in humans (Pastoureau et al., 1988; 1991).

\section{Seasonal changes of bone mineral density (BMD)}

Seasonal changes of BMD in humans, with lower bone mass during winter and higher bone mass in summer are well described (Rosen et al., 1994; Aitken et al., 1973; Bergstralh et al., 1990; Hyldstrup et al., 1986; Krolner, 1983). Different groups have demonstrated that BMD and bone turnover parameters also change significantly in sheep throughout the year (Hornby et al., 1995; Chavassieux et al., 1991). Arens et al. (2007) stated that nearly half of BMD changes of up to $10 \%$ following ovariectomy, may in fact be caused by seasonal changes, and therefore appropriate control groups are essential and experiments should - whenever possible - span all four seasons to minimise these effects (Turner, 2002).

Furthermore, it has to be taken into account that BMD and bone mineral content (BMC) are significantly higher in sheep compared to humans. Aerssens et al. (1998), for example, examined the lumbar spine of different species

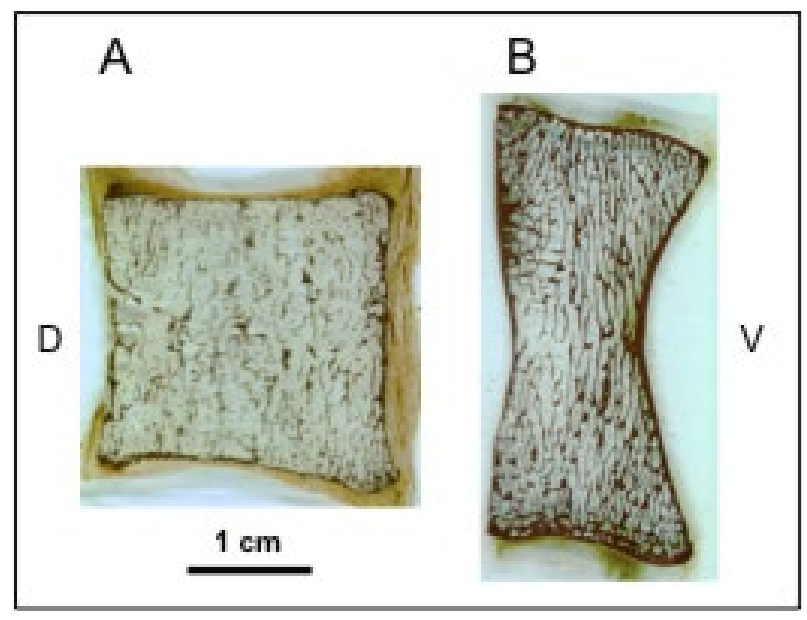

Fig. 2. Differences in static and biomechanical load of bipeds and quadrupeds cause relevant anatomical and morphological differences between the human and sheep spine. Bone mass and mineral content is much higher in sheep. Mid-sagittal view of (A) lumbar spine (L4) of aged human in comparison to (B) lumbar spine (L4) of aged ewe (D - dorsal, V - ventral).

and reported mean BMD values for humans of $\sim 180 \mathrm{mg} /$ $\mathrm{cm}^{3}$ and for sheep of $\sim 40 \mathrm{mg} / \mathrm{cm}^{3}$. Mean BMC values in sheep were also found to be increased by two- to four-fold (human $\sim 80 \mathrm{mg}$, sheep $\sim 240 \mathrm{mg}$ ). These structural changes result in an even more pronounced increase in mechanical stability (fracture stress $\left(\mathrm{N} / \mathrm{mm}^{2}\right)$ human $v s$. sheep: $\sim 1.2$ vs. $\sim 13.2=$ ten-fold); the latter might explain why even ewes with marked bone-loss still show relatively high $\mathrm{BMD}$ and $\mathrm{BMC}$ values, and osteoporotic fractures have not been reported in these animals.

\section{Of note}

In all quadrupeds, it is obvious that the static and biomechanical loads - especially of the spine - are different from those in humans (Reinwald and Burr, 2008). In particular, the lumbar spine of ewes is slightly kyphotic rather than lordotic (Wilke et al., 1997) and cancellous BMD can reach extraordinary levels $\left(400-600 \mathrm{mg} / \mathrm{cm}^{3}\right)$ (Aerssens et al., 1998) (Fig. 2). In addition, positioning of the femoral neck region, in particular (Turner, 2002), but also the spine (Deloffre et al., 1995), on the Dual-energy X-ray absorptiometry (DXA) for measuring BMD can be technically difficult.

A major disadvantage of the ewe as an animal model is the different gastrointestinal system characterised by a complex four-compartment stomach (herbivore/ruminant). It is therefore not suitable for studies dealing with orally administered drugs or studies in which oral absorption of any agent is of major interest (Turner, 2002; Reinwald and Burr, 2008).

Another difference to human physiology is phosphorus metabolism. In contrast to humans, the gastrointestinal tract of sheep is the major route for phosphate elimination, which results in a minimal urinary excretion of phosphate (O’Connell, 1999). Furthermore, drug dosages and clearance rates can be difficult to calculate since the 


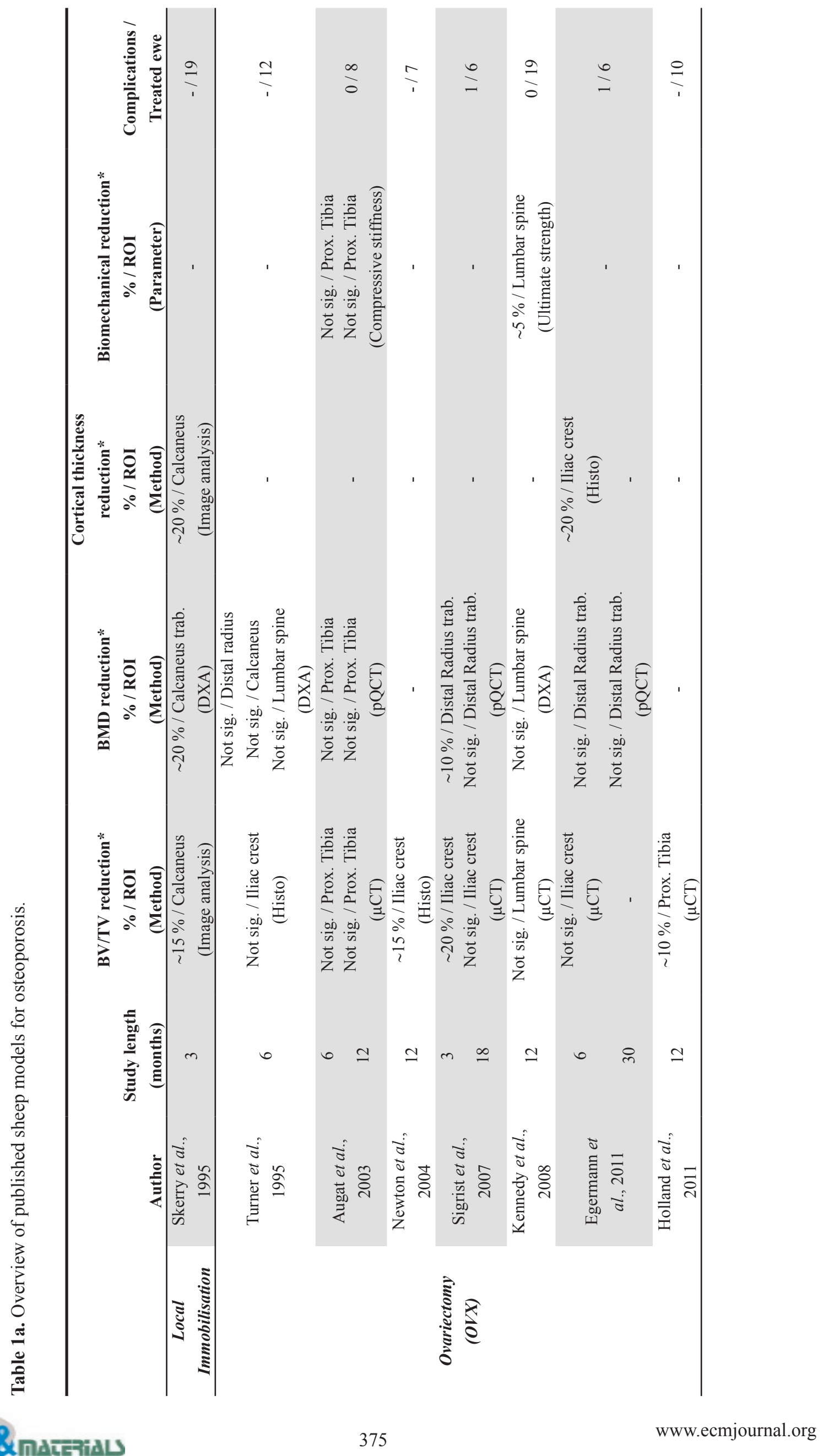




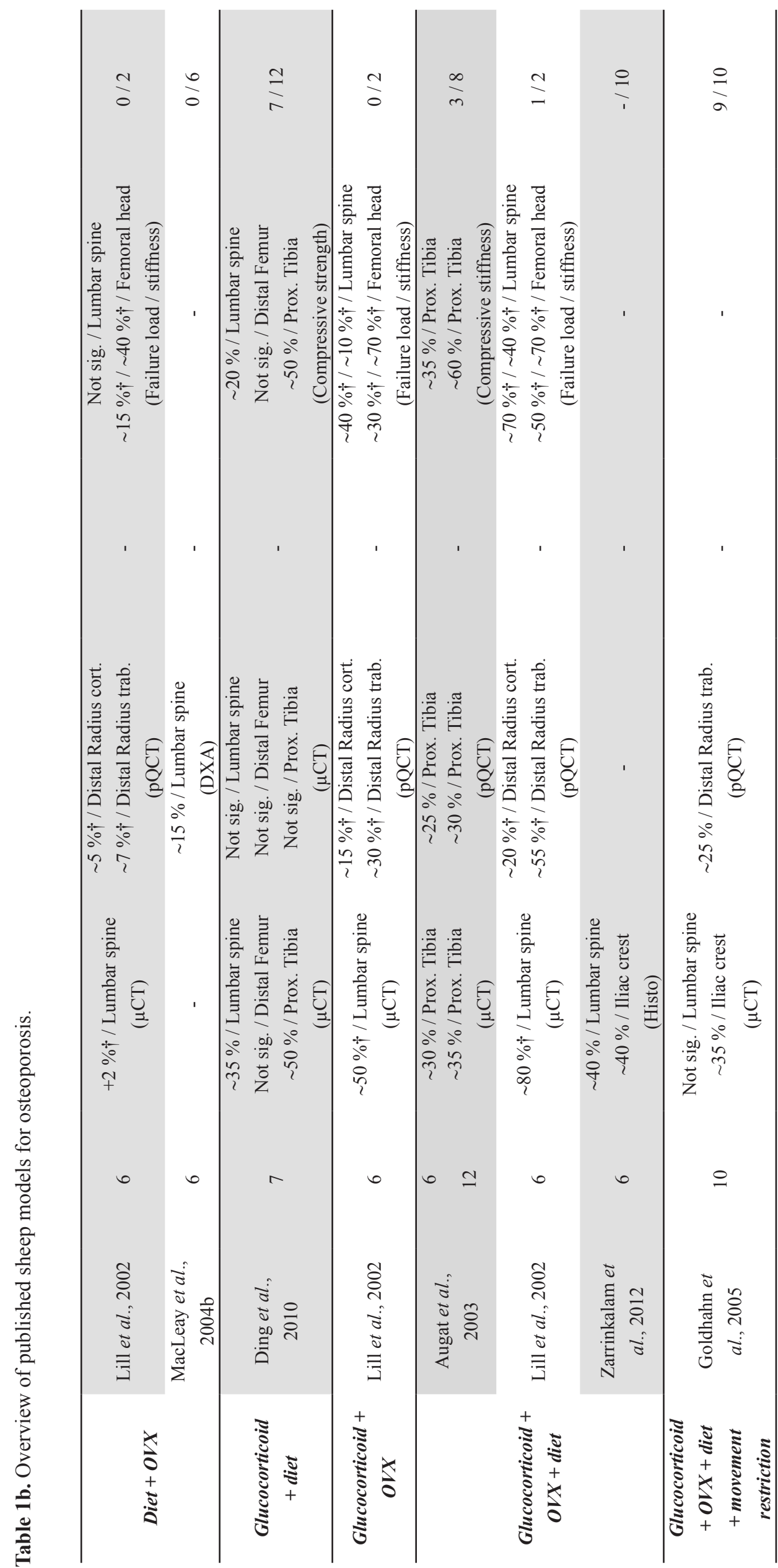




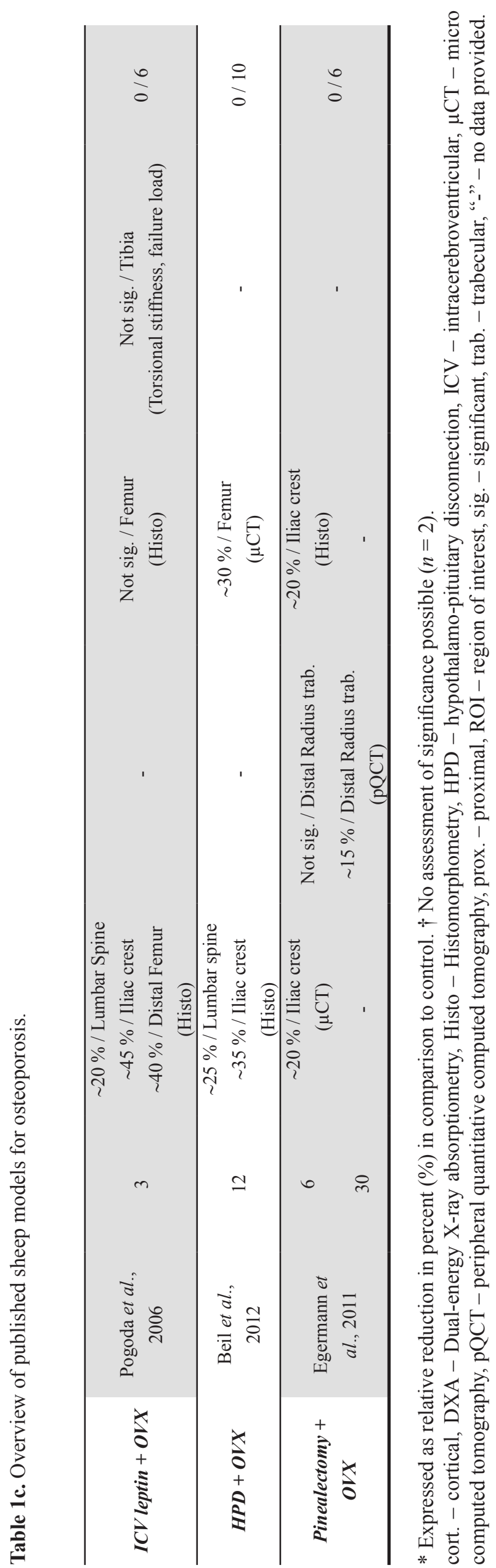

body weight of sheep can be significantly influenced by rumen fluid $(\sim 10 \%)$ and fleece and pelt weight $(\sim 10 \%)$ (Mahmood et al., 2006). Dietary considerations play an important role as well, since the feed can be rich in calcium and/or leguminous silages. These silages can be rich in phyto-oestrogenic compounds, which act as selective oestrogen receptor modulators (SERMs) and therefore interfere with the hormonal regulation of bone mass (Chavassieux et al., 2001; Reinwald and Burr, 2008).

Taken together, the ewe is an appropriate and attractive model for bone disorders in general and osteoporosis in particular; however, results of experiments have to be interpreted against the background of strain, age, season, diet, skeletal site and hormone-cycle characteristics, and appropriate controls are crucial. Furthermore, besides the magnitude of bone loss, animal welfare is becoming increasingly important to society as well as scientists.

\section{Ewe models for osteoporosis}

As mentioned above, the sheep is well established as a model for human bone loss/osteoporosis in orthopaedic research. Predominantly aged or ovariectomised ewes, as well as glucocorticoid sheep models, have been used in the past for studying bone metabolism and implants. Up to date there are several sheep studies published focussing on fracture healing (Claes et al., 1998; Manjubala et al., 2009) and orthopaedic implant/bone substitute research (Cunin et al., 2000; Fini et al., 2003; Stadelmann et al., 2008; Verron et al., 2010; Babiker et al., 2012; Shapiro et al., 2012). Furthermore, vertebral (Thomas et al., 2008) and dental implants (Ferguson et al., 2008) as well as antiosteoporotic drugs, such as parathyroid hormone (PTH 1-34) and SERMs (Delmas et al., 1995; Chavassieux et al., 2001), have also been successfully studied in sheep. On the following pages, different sheep models for bone loss induction will be introduced and compared.

\section{Immobilisation}

Sufficient immobilisation of an extremity in sheep can be achieved by the use of an external fixator. This approach is suitable to induce a significant reduction of BMD of local cancellous bone (calcaneus) of up to $20 \%$ (Skerry and Lanyon, 1995; Thomas et al., 1995). This reduction was also found when the ewes were allowed to bear the leg with full-weight for $20 \mathrm{~min}$ per day. However, besides the need of a surgical approach and custom-made implants, the impairment of movement and comfort of the sheep is a disadvantage of this model. In addition, the observed changes in bone mass and structure are only found locally and not systemically as would be seen in osteoporotic patients.

Other groups have used movement restriction to further pronounce bone loss in sheep, initially induced by ovariectomy combined with glucocorticoid-therapy (Goldhahn et al., 2005; 2006). In our opinion, the marked impact on bone mass and structure by this general movement restriction cannot be judged objectively and impairs animal welfare and thus should be avoided (Table 1). 


\section{Ovariectomy (OVX)}

The ovariectomy in sheep is a simple and safe surgical approach. Although BMD reduction is reported 6 months after OVX in the lumbar spine (Turner et al., 1995) and 3 months after OVX in the distal radius (Sigrist et al., 2007), long-term studies questioned the sustainability of the described bone loss. Several groups demonstrated that the bone loss of extremities and lumbar spine induced by OVX reaches a maximum after 3-4 months; thereafter, BMD levels and bone turnover markers stabilised and returned to pre-OVX levels around 6 months after OVX (Augat et al., 2003; MacLeay et al., 2004a; Pogoda et al., 2006; Sigrist et al., 2007). Histomorphometric analyses by our group could show that in sheep, 3 months after OVX, an increase in bone resorption is compensated for by a simultaneous increase in bone formation, explaining the observed rebound effect (Pogoda et al., 2006). Brennan et al. (2011) demonstrated that the apoptosis rate of osteocytes in ewes 12 and 31 months after OVX was significantly increased, whereas mean length and density of micro-cracks were not significantly changed in comparison to untreated controls.

Although Kennedy et al. (2008) could not find BMD changes even 12 months after OVX but only an increased bone turnover, other groups could show significant changes in bone mass and micro-structural parameters of ewes at this time (Johnson et al., 2002; Newton et al., 2004; Holland et al., 2011). This potential long-term effect of OVX was supported by data from 24-monthtrials that reported significant changes in structural parameters (trabecular thickness and number), as well as biomechanical properties (maximum load, strength and elastic modules) in OVX ewes in comparison to control animals (Fini et al., 2000; Giavaresi et al., 2001). Furthermore, the relevance of hormonal influences on bone metabolism in sheep is underlined by the fact that oestrogen therapy, as well as therapy with selective oestrogen receptor modulators (SERMs), is able to significantly increase bone mass in sheep (Turner et al., 1995; Chavassieux et al., 2001). SERMs act differently on oestrogen receptors in various tissues and are therefore neither pure agonists nor pure antagonists. Some SERMs - such as Raloxifen - act as oestrogen agonists in bone but as antagonists in breast and uterus tissue, which is why they are advantageous in the treatment of postmenopausal osteoporosis as they mimic positive oestrogen effects on bone by avoiding negative effects on breast and uterus tissue (cancer risk).

In any case, the study design should take into account that most sheep breed seasonally, thus sensitivity of bone metabolism on oestrogen deficiency varies with the season (Healy et al., 2010).

In conclusion, the influence of oestrogen on bone metabolism in ewes seems to be comparable to those in humans, although significant changes in bone mass and/ or structural parameters are due to a distinct compensation mechanism difficult to predict. As described above, ovariectomy in sheep leads to rapid and significant bone loss within the first 3 months after OVX; this effect is compensated within the first 12 months after surgery, most likely due to an increase in bone formation. Some studies suggest that ovariectomy might result in significant impairment of bone mass and microarchitecture after long term ( $\geq 12$ months). However, contrary data for this timeperiod have also been published. This issue underlines the importance of considering seasonal changes of BMD in ewes when interpreting experimental data (Table 1).

\section{Glucocorticoids}

Glucocorticoid therapy in sheep leads to bone loss and microarchitectural changes with biomechanical impairment comparable to that described in humans (Chavassieux et al., 1993; Ding et al., 2010). This model is probably the most common sheep model for osteoporosis and has been shown to affect cortical as well as trabecular bone (Lill et al., 2002; Schorlemmer et al., 2003). Different glucocorticoid application regimes are used, such as daily injections of $0.6 \mathrm{mg} / \mathrm{kg}$ prednisolone (Ding et al., 2010; Augat et al., 2003) or 15-25 mg methylprednisolone (Deloffre et al., 1995; Lill et al., 2002), versus 500 mg methylprednisolone every 3 weeks (Klopfenstein Bregger et al., 2007). These regimes induce significant impairment of bone mass and structure, and subsequently mechanical qualities as well as bone turnover parameters after several $(\sim 6)$ months. For example, bone volume, defined as bone volume/tissue volume (BV/TV), of the lumbar spine was found to have declined by $35-50 \%$ in comparison to the control group (Lill et al., 2002; Schorlemmer et al., 2003). Ding et al. (2010) demonstrated that this glucocorticoid effect cannot be prevented by an intact oestrous cycle. In particular, ewes without OVX also show a significant impact on bone mass.

Advantages of this approach are the ease and reliability of induction of pronounced bone loss. However, there are two major disadvantages: firstly, the sustainability of the bone mass and structural changes depends on continued glucocorticoid injections (Ding et al., 2010; Goldhahn et al., 2005); secondly, severe side effects such as massive infections and hair-loss may occur, especially in high-dose regimes (Ding et al., 2010; Lill et al., 2002; Schorlemmer et al., 2003; Goldhahn et al., 2005). As these severe side effects cannot be overlooked (Egermann et al., 2008), efforts to improve this model were undertaken by different groups. Klopfenstein Bregger et al. (2007) showed that adverse side effects can be reduced by decreasing the number of glucocorticoid administrations (using equal total amounts) without reducing the impact on bone.

In conclusion, glucocorticoid therapy in ewes induces significant-to-dramatic reduction of BMD, and microarchitectural deterioration after several $(\sim 6)$ months; this is comparable to conditions found in glucocorticoidtreated humans. Disadvantages of this model include the distinctly compromised animal welfare, especially in treatment regimes based on daily injections of highdose methyl-/prednisone. The latter not only constitutes ethical concerns but also extremely limits the value of this model, as systemic side effects preclude studying skeletal physiology in bone loss situations. Further studies are necessary to improve study designs in terms of glucocorticoid dosage and application interval to reduce severe adverse effects (Table 1). 


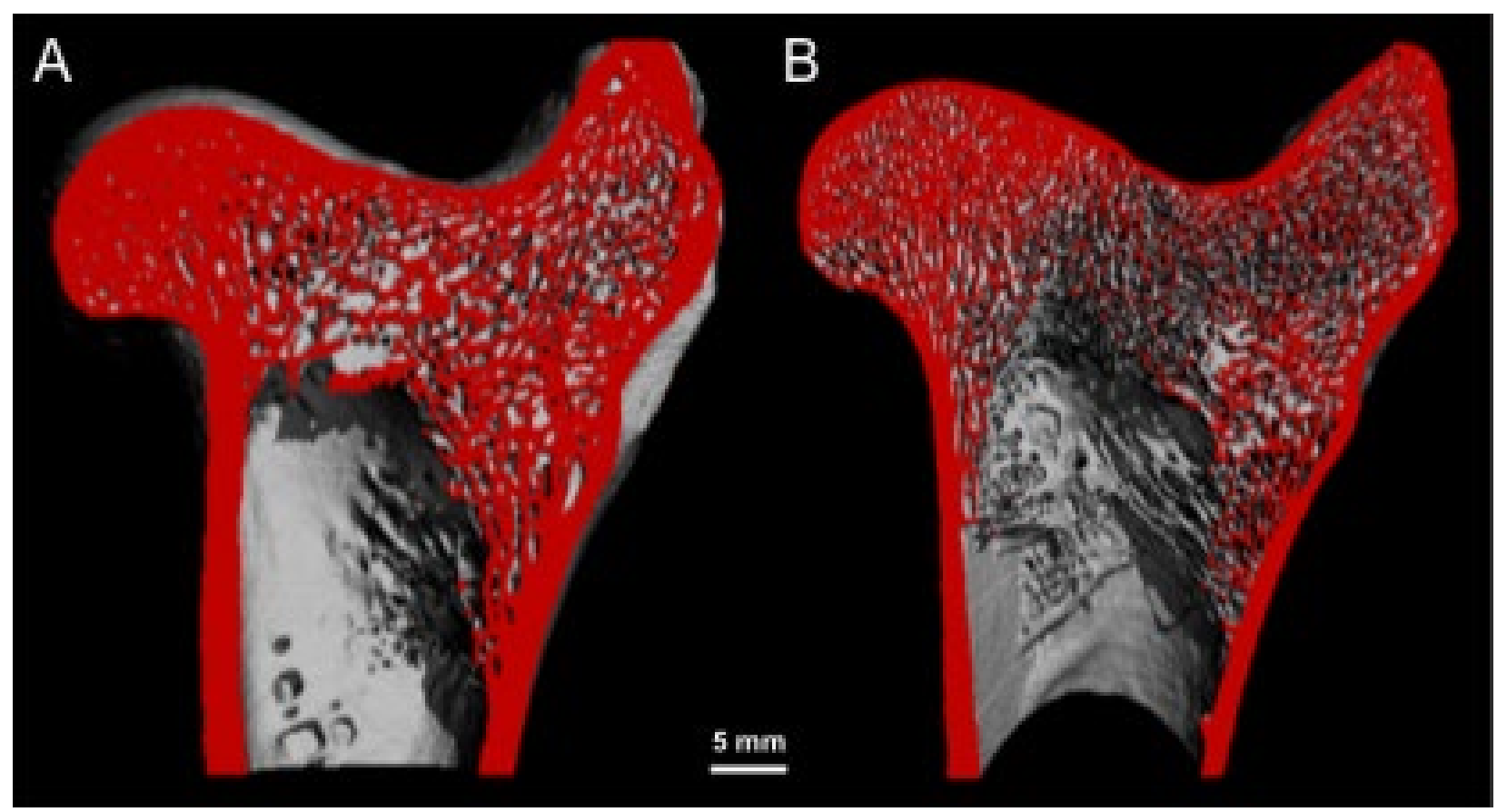

Fig. 3. Bone mass and structure is centrally controlled in mammalians. The surgical Hypothalamo-pituitary disconnection (HPD) leads to significant bone loss of both cortical and trabecular bone in sheep. Frontal view of highresolution peripheral quantitative computed tomography (HR-pQCT - XtremeCT ${ }^{\circledR}$, Scanco Medical, Switzerland) of (A) proximal femur of untreated control ewe and (B) of ewe 24 months post HPD procedure.

\section{Diet}

Calcium and vitamin D restriction is often supportively used to negatively influence bone turnover in sheep. Lill et al. (2002) established for instance a restricted diet containing $1.5 \mathrm{~g}$ calcium and $100 \mathrm{IU}$ vitamin D3 per day, whereas the standard feed contains $5 \mathrm{~g}$ calcium and $1000 \mathrm{IU}$ vitamin D3 per day. If this regime is augmented by OVX and glucocorticoid therapy, the impact on bone mass is dramatic. After 6 months of treatment decline of BV/TV by $60-80 \%$ and BMD reduction of up to $60 \%$ is reported for this triple combination in comparison to control (Lill et al., 2002; Augat et al., 2003; Schorlemmer et al., 2003; Zarrinkalam et al., 2012; Veigel et al., 2011). In contrast, the impact on bone metabolism by dietary restriction in combination with OVX alone is limited as reported by Lill et al. (2002) - decrease of BMD of 5\% in cortical bone and $\sim 7 \%$ in cancellous bone of the distal radius of two sheep in comparison to control.

Additionally, MacLeay et al. (2004b) showed that dietary-induced metabolic acidosis (DIMA) alone or in combination with OVX is also able to influence bone turnover. Metabolic acidosis was in this model induced by limiting the amount of potassium and adding magnesium, sodium, sulphur and chloride to the diet. The compensated metabolic acidosis was monitored by measurements of arterial $\mathrm{pH}$ values. After 6 months of treatment, BMD of the lumbar spine measured by DXA was found reduced by about $15 \%$ in combination with OVX. However, diet alone could not reduce the BMD significantly, but only influence bone turnover parameters.

Taken together, the impact on bone mass by just dietary measures seems to be limited and strict diet regimes can, in general, only be implemented if the sheep are housed 'in- house' or even in metabolic cages. The latter, in particular, impairs the comfort of the animals. Moreover, further studies are necessary to improve study designs in terms of dietary specifications and duration (Table 1).

\section{Polypragmatic concepts}

To prevent protective effects of oestrogen on bone loss, ovariectomy became a standard procedure in almost every model for bone loss induction. However, in our opinion polypragmatic regimes, such as combination of OVX + glucocorticoid therapy + diet restriction + movement restriction (Goldhahn et al., 2005; 2006) can never be justified by any gain of knowledge. As noted by Egermann et al. (2008), "the severity of the side-effects cannot be overlooked", but the side effects induced by massive therapeutic interventions cannot be accepted, thus these models are doubtless obsolete. Since all experts in the field understand this, efforts to improve these models are underway (Klopfenstein Bregger et al., 2007). Furthermore, various influences on bone metabolism complicate the already complex system of bone regulation in mammals - rather than simplify it - and this should be part of animal models (Table 1).

\section{Central bone regulation}

Experiments in rodents allowed us to gain a deeper understanding of central bone regulation. Leptin, in particular, became very attractive as a potential candidate for further investigations of this superordinate system (Foldes et al., 1992; Mathey et al., 2002; Tamasi et al., 2003; Thomas, 2003; Martin et al., 2005). To answer the question whether leptin is also important in bone regulation in large remodelling animals, Pogoda et al. (2006) implemented 


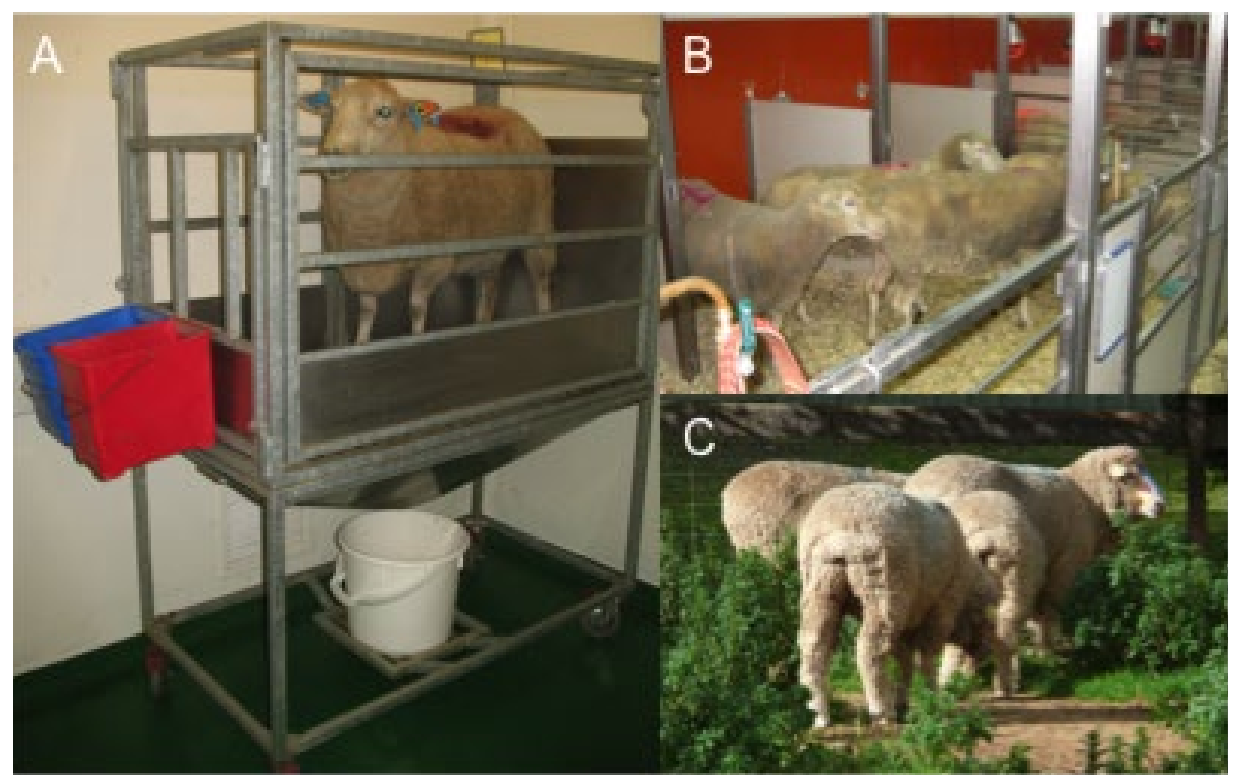

Fig. 4. Ethical issues and large animal models. Example: different types of sheep housing. (A) Metabolic cage, (B) Group housing in house, (C) Group housing on pasture. Animal welfare is supposed to improve from A to $\mathrm{C}$.

an ewe model consisting of intracerebroventricular (ICV) application of recombinant leptin (Oheim et al., 2012). After 3 months of treatment, the ICV leptin ewes showed a significant decline in bone formation of $\sim 70 \%$ and BV/TV reduction of $\sim 45 \%$ in comparison with controls, whereas mechanical properties (torsional stiffness, failure load) did not change significantly. Although this model generated essential insights into central bone regulation, it is not appropriate as a regular model for studying osteoporosis. Disadvantages include the high costs of recombinant leptin, meaning experiments over a period of 6 or even 12 months are simply not affordable. Furthermore, surgery is very demanding and depends on special neurosurgical equipment, such as a stereotactic frame and intra-operative $\mathrm{X}$-ray visualisation of the ventricle system.

Subsequently, our group implemented a central controlled model for low turnover osteoporosis beyond the leptin signalling pathway by surgical disconnection of the hypothaloma-pituitary axis (HPD) (Beil et al., 2012). This demanding surgical approach is sufficient to implement a profound bone loss that affects both cortical (reduction of cortical thickness of femur $30 \%$ ) and trabecular bone (reduction of BV/TV of iliac crest $\sim 35 \%$ ). Histomorphometric analyses indicated that the observed bone loss is due to a maximised low turnover situation with simultaneously depressed osteoblast and osteoclast function. The pronounced bone loss developed continuously over time and was sustained without any further treatment (Fig. 3). The latter fact is very important in reducing experimental costs and manpower, as well as improving animal welfare. However, surgical disconnection of the pituitary gland from the hypothalamus leads obviously to several systemic alterations, such as hormonal changes of gonadotropin (LH, FSH), thyroid hormones (T3, T4), insulin-like growth factor 1 (IGF-1), cortisol, and leptin (Beil et al., 2012). These systemic interactions need to be considered when interpreting results generated in this model.

Another large animal model for central bone regulation is based on melatonin deficiency caused by surgical pinealectomy (Egermann et al., 2011). Melatonin is secreted centrally by the pineal gland but also by bone marrow cells (Conti et al., 2000) and is therefore potentially able to play an important role in regulation of bone metabolism (Cardinali et al., 2003). It has already been demonstrated that melatonin has a significant influence on osteoblast activity, proliferation and differentiation (Roth et al., 1999; Radio et al., 2006) as well as on BMD and bone structure (Koyama et al., 2002). Egermann et al. (2011) described a ewe model of osteoporosis after pinealectomy, with or without combination of OVX. After 6 months, significant reduction of BV/TV of $\sim 10 \%$ of the iliac crest was observed in comparison to control. The BMD of the distal radius declined by $\sim 15 \%$ during an observation of 30 months. A smaller, but still significant, reduction in BV/TV and BMD could be observed in pinealectomised animals without OVX. Although the reduction of BMD and BV/TV was small in this model, the decrease was significant, and beside the initial surgical approach, no other treatment was performed; this is - similar to the HPD-model - beneficial to animal welfare and cost reduction (Table 1).

Sheep models of centrally induced bone loss are doubtless very complex systems and due to their polysystemic changes hardly comparable to the situation found in patients suffering from postmenopausal osteoporosis. Nevertheless, these models might be valuable for studying new implants and/or bone substitutes due their significant and reliable bone loss. On the other hand, it is quite conceivable that anti-osteoporotic drugs might also be tested in these models. As it is recommended for all animal models, thorough characterisation of the model is in this case of crucial importance. The HPD model, for example, 
Table 2. Main characteristics of different sheep models for osteoporosis.

\begin{tabular}{|c|c|c|c|c|c|c|c|}
\hline Model & $\begin{array}{c}\text { Surgical } \\
\text { procedure }\end{array}$ & $\begin{array}{c}\text { Surgery } \\
\text { costs } \\
\end{array}$ & Handling & $\begin{array}{c}\text { Running } \\
\text { costs } \\
\end{array}$ & $\begin{array}{l}\text { Extend of } \\
\text { bone loss }\end{array}$ & $\begin{array}{c}\text { Sustainability } \\
\text { of bone loss }\end{array}$ & $\begin{array}{c}\text { Ethical } \\
\text { concerns }\end{array}$ \\
\hline Local Immobilisation & Medium & Medium & Medium & Low & Low & No & Medium \\
\hline Ovariectomy $(\mathrm{OVX})$ & Simple & Low & Simple & Low & Low & No & Low \\
\hline Diet $+O V X$ & Simple & Low & Medium & Low & Low & No & Medium \\
\hline Glucocorticoid + diet & - & - & Medium & Low & Medium - High & No & High \\
\hline $\begin{array}{c}\text { Glucocorticoid }+ \\
\text { OVX }\end{array}$ & Simple & Low & Medium & Low & Medium - High & No & High \\
\hline $\begin{array}{c}\text { Glucocorticoid }+ \\
\text { OVX }+ \text { diet }\end{array}$ & Simple & Low & Medium & Medium & Medium - High & No & High \\
\hline $\begin{array}{c}\text { Glucocorticoid } \\
+ \text { OVX }+ \text { diet }+ \\
\text { movement restriction }\end{array}$ & Simple & Low & Complex & Medium & Medium - High & No & $\begin{array}{c}\text { Extremely } \\
\text { high }\end{array}$ \\
\hline ICV leptin $+O V X$ & $\begin{array}{c}\text { Very } \\
\text { demanding }\end{array}$ & High & Complex & $\begin{array}{l}\text { Very } \\
\text { high }\end{array}$ & Medium & No & Medium \\
\hline$H P D+O V X$ & $\begin{array}{c}\text { Very } \\
\text { demanding }\end{array}$ & High & Simple & Low & Medium - High & Yes & Low \\
\hline Pinealectomy $+O V X$ & Demanding & High & Simple & Low & Low & Yes & Low \\
\hline
\end{tabular}

HPD - hypothalamo-pituitary disconnection, ICV - intracerebroventricular.

seems attractive to study effects of anti-osteoporotic drugs in a pronounced low-turnover situation, in contrast to the high-turnover situation typically found in patients suffering from postmenopausal osteoporosis.

\section{Conclusion}

Although many issues in bone research can be addressed in vitro or in rodent animal models, some questions can only be discussed against the background of a complex mammalian system of large remodelling animals, and sometimes size does matter e.g. for orthopaedic implants. The ewe is - due to its similarities in bone structure, metabolism and hormonal regulation - a suitable large animal model for human bone disorders and has already proven its great value for this research in many different studies. Furthermore, sheep have simple husbandry needs, a compliant nature, are available in large numbers and costs for acquisition and maintenance are low. Finally yet importantly, societal and ethical implications are low compared to other large animal models. However, choosing the right ewe model should not only depend on the biggest impact on bone mass or structure but also on animal welfare. Considering that sheep are herd animals, stress can be reduced by group housing - on pasture if possible - and by avoiding daily treatment (Fig. 4).

The ovariectomised ewe as a model for osteoporosis appears unsuitable due to its unreliable rebound effect and has only minor impact on bone metabolism. However, oestrogen deficiency does have an influence on bone metabolism in sheep. Glucocorticoid treatment, on the other hand, has a major impact on bone turnover and leads to bone conditions comparable to those found in steroid-treated humans. This concept might be suitable as a model for glucocorticoid-induced osteoporosis. However, adverse side effects can be dramatic resulting in unacceptable discomfort and illness of the experimental animals, thus it is essential to further improve this model to allow it to be judged as ethically appropriate. Models for osteoporosis induced by intervention of central regulatory mechanisms have been successfully established recently and underline the important role of these mechanisms in large remodelling animals. Beside the new insights these models can give into the underlying mechanisms of central bone regulation, they appear attractive as remarkable bone loss is induced by only one surgical procedure without any further treatment (Table 2).

\section{Acknowledgements}

We wish to confirm that there are no known conflicts of interest associated with this publication and there has been no significant financial support for this work that could have influenced its outcome. This work was supported within the framework of the DFG Forschergruppe 793 to $\mathrm{MA}, \mathrm{PP}$, and AI. 


\section{References}

Aerssens J, Boonen S, Lowet G, Dequeker J (1998) Interspecies differences in bone composition, density, and quality: potential implications for in vivo bone research. Endocrinology 139: 663-670.

Aitken JM, Anderson JB, Horton PW (1973) Seasonal variations in bone mineral content after the menopause. Nature 241: 59-60.

Arens D, Sigrist I, Alini M, Schawalder P, Schneider E, Egermann M (2007) Seasonal changes in bone metabolism in sheep. Vet J 174: 585-591.

Augat P, Schorlemmer S, Gohl C, Iwabu S, Ignatius A, Claes L (2003) Glucocorticoid-treated sheep as a model for osteopenic trabecular bone in biomaterials research. J Biomed Mater Res A 66: 457-462.

Babiker H, Ding M, Sandri M, Tampieri A, Overgaard S (2012) The effects of bone marrow aspirate, bone graft, and collagen composites on fixation of titanium implants. J Biomed Mater Res B Appl Biomater 100: 759-766.

Beil FT, Oheim R, Barvencik F, Hissnauer TN, Pestka JM, Ignatius A, Rueger JM, Schinke T, Clarke IJ, Amling M, Pogoda P (2012) Low turnover osteoporosis in sheep induced by hypothalamic-pituitary disconnection. J Orthop Res 30: 1254-1262.

Bergstralh EJ, Sinaki M, Offord KP, Wahner HW, Melton LJr (1990) Effect of season on physical activity score, back extensor muscle strength, and lumbar bone mineral density. J Bone Miner Res 5: 371-377.

Bonjour JP, Ammann P, Rizzoli R (1999) Importance of preclinical studies in the development of drugs for treatment of osteoporosis: a review related to the 1998 WHO guidelines. Osteoporos Int 9: 379-393.

Borsari V, Fini M, Giavaresi G, Rimondini L, Consolo U, Chiusoli L, Salito A, Volpert A, Chiesa R, Giardino R (2007) Osteointegration of titanium and hydroxyapatite rough surfaces in healthy and compromised cortical and trabecular bone: in vivo comparative study on young, aged, and estrogen-deficient sheep. J Orthop Res 25: 1250-1260.

Brennan O, Kennedy OD, Lee TC, Rackard SM, O'Brien FJ (2011) Effects of estrogen deficiency and bisphosphonate therapy on osteocyte viability and microdamage accumulation in an ovine model of osteoporosis. J Orthop Res 29:419-424.

Cardinali DP, Ladizesky MG, Boggio V, Cutrera RA, Mautalen C (2003) Melatonin effects on bone: experimental facts and clinical perspectives. J Pineal Res 34: 81-87.

Chavassieux P, Pastoureau P, Boivin G, Delmas PD, Chapuy MC, Meunier PJ (1991) Effects of osseinhydroxyapatite compound on ewe bone remodeling: biochemical and histomorphometric study. Clin Rheumatol 10: $269-273$.

Chavassieux P, Pastoureau P, Chapuy MC, Delmas PD, Meunier PJ (1993) Glucocorticoid-induced inhibition of osteoblastic bone formation in ewes: a biochemical and histomorphometric study. Osteoporos Int 3: 97-102.

Chavassieux P, Garnero P, Duboeuf F, Vergnaud P, Brunner-Ferber F, Delmas PD, Meunier PJ (2001) Effects of a new selective estrogen receptor modulator (MDL
103,323 ) on cancellous and cortical bone in ovariectomized ewes: a biochemical, histomorphometric, and densitometric study. J Bone Miner Res 16: 89-96.

Checa S, Prendergast PJ, Duda GN (2011) Inter-species investigation of the mechano-regulation of bone healing: Comparison of secondary bone healing in sheep and rat. $\mathrm{J}$ Biomech 44: 1237-1245.

Chrischilles EA, Butler CD, Davis CS, Wallace RB (1991) A model of lifetime osteoporosis impact. Arch Intern Med 151: 2026-2032.

Claes LE, Heigele CA, Neidlinger-Wilke C, Kaspar D, Seidl W, Margevicius KJ, Augat P (1998) Effects of mechanical factors on the fracture healing process. Clin Orthop Relat Res 355: S132-S147.

Conti A, Conconi S, Hertens E, Skwarlo-Sonta K, Markowska M, Maestroni JM (2000) Evidence for melatonin synthesis in mouse and human bone marrow cells. J Pineal Res 28: 193-202.

Corlett SC, Couch M, Care AD, Sykes AR (1990) Measurement of plasma osteocalcin in sheep: assessment of circadian variation, the effects of age and nutritional status and the response to perturbation of the adrenocortical axis. Exp Physiol 75: 515-527.

Cunin G, Boissonnet H, Petite H, Blanchat C, Guillemin G (2000) Experimental vertebroplasty using osteoconductive granular material. Spine 25: 1070-1076.

Currey JD (2002) Bones: Structure and Mechanics, Princeton University Press, Princeton, Chapter 1, The structure of bone tissue, pp 3-26.

Delmas PD, Vergnaud P, Arlot ME, Pastoureau P, Meunier PJ, Nilssen MHL (1995) The anabolic effect of human PTH (1-34) on bone formation is blunted when bone resorption is inhibited by the bisphosphonate tiludronateis activated resorption a prerequisite for the in vivo effect of PTH on formation in a remodeling system? Bone 16: 603-610.

Deloffre P, Hans D, Rumelhart C, Mitton D, Tsouderos Y, Meunier PJ (1995) Comparison between bone density and bone strength in glucocorticoid-treated aged ewes. Bone 17: 409S-414S.

Ding M, Cheng L, Bollen P, Schwarz P, Overgaard S (2010) Glucocorticoid induced osteopenia in cancellous bone of sheep: validation of large animal model for spine fusion and biomaterial research. Spine 35: 363-370.

Egermann M, Goldhahn J, Holz R, Schneider E, Lill CA (2008) A sheep model for fracture treatment in osteoporosis: benefits of the model versus animal welfare. Lab Anim 42: 453-464.

Egermann M, Gerhardt C, Barth A, Maestroni GJ, Schneider E, Alini M (2011) Pinealectomy affects bone mineral density and structure - an experimental study in sheep. BMC Musculoskelet Disord 12: 271.

Ferguson SJ, Langhoff JD, Voelter K, Rechenberg B, Scharnweber D, Bierbaum S, Schnabelrauch M, Kautz AR, Frauchiger VM, Mueller TL (2008) Biomechanical comparison of different surface modifications for dental implants. Int J Oral Maxillofac Implants 23: 1037-1046.

Fini M, Pierini G, Giavaresi G, Biagini G, Mattioli Belmonte MM, Nicoli Aldini N, Rocca M, Martini L, Giardino R (2000) The ovariectomised sheep as a model for 
testing biomaterials and prosthetic devices in osteopenic bone: a preliminary study on iliac crest biopsies. Int J Artif Organs 23: 275-281.

Fini M, Giavaresi G, Greggi T, Martini L, Aldini NN, Parisini P, Giardino R (2003) Biological assessment of the bone-screw interface after insertion of uncoated and hydroxyapatite-coated pedicular screws in the osteopenic sheep. J Biomed Mater Res Part A 66: 176-183.

Foldes J, Shih MS, Levy J (1992) Bone structure and calcium metabolism in obese Zucker rats. Int J Obes Relat Metab Disord 16: 95-102.

Giavaresi G, Fini M, Torricelli P, Martini L, Giardino $\mathrm{R}$ (2001) The ovariectomized ewe model in the evaluation of biomaterials for prosthetic devices in spinal fixation. Int J Artif Organs 24: 814-820.

Goldhahn J, Jenet A, Schneider E, Lill CA (2005) Slow rebound of cancellous bone after mainly steroid-induced osteoporosis in ovariectomized sheep. J Orthop Trauma 19: $23-28$.

Goldhahn J, Neuhoff D, Schaeren S, Steiner B, Linke B, Aebi M, Schneider E (2006) Osseointegration of hollow cylinder based spinal implants in normal and osteoporotic vertebrae: a sheep study. Arch Orthop Trauma Surg 126: 554-561.

Goodman RL (1994) Neuroendocrine control of the ovine estrous cycle. In: Knobil E, Neill JD (eds) The Physiology of Reproduction. Raven Press, New York, pp 659-709.

Hazzard DG, Bronson RT, McClearn GE, Strong R (1992) Selection of an appropriate animal model to study aging processes with special emphasis on the use of rat strains. J Gerontol 47: B63-64.

Healy C, Kennedy OD, Brennan O, Rackard SM, O'Brien FJ, Lee TC (2010) Structural adaptation and intracortical bone turnover in an ovine model of osteoporosis. J Orthop Res 28: 248-251.

Holland JC, Brennan O, Kennedy OD, Rackard SM, O’Brien FJ, Lee TC (2011) Subchondral trabecular structural changes in the proximal tibia in an ovine model of increased bone turnover. J Anat 218: 619-624.

Hornby SB, Ford SL, Mase CA, Evans GP (1995) Skeletal changes in the ovariectomised ewe and subsequent response to treatment with 17 beta oestradiol. Bone 17: 389S-394S.

Hyldstrup L, McNair P, Jensen GF, Transbol I (1986) Seasonal variations in indices of bone formation precede appropriate bone mineral changes in normal men. Bone 7: 167-170.

Johnson RB, Gilbert JA, Cooper RC, Parsell DE, Stewart BA, Dai X, Nick TG, Streckfus CF, Butler RA, Boring JG (2002) Effect of estrogen deficiency on skeletal and alveolar bone density in sheep. J Periodontol 73: 383 391.

Kalu DN (1999) Animal models of the aging skeleton. In: Rosen CJ, Glowacki J, Bilezikian JP (eds) The Aging Skeleton, Academic Press, San Diego, pp 37-50.

Kennedy OD, Brennan O, Mahony NJ, Rackard SM, O'Brien FJ, Taylor D, Lee CT (2008) Effects of high bone turnover on the biomechanical properties of the L3 vertebra in an ovine model of early stage osteoporosis. Spine 33: 2518-2523.
Kerschnitzki M, Wagermaier W, Liu Y, Roschger P, Duda GN, Fratzl P (2011) Poorly Ordered Bone as an Endogenous Scaffold for the Deposition of Highly Oriented Lamellar Tissue in Rapidly Growing Ovine Bone. Cells Tissues Organs 194: 119-123.

Klopfenstein Bregger MD, Schawalder P, Rahn B, Eckhardt C, Schneider E, Lill C (2007) Optimization of corticosteroid induced osteoporosis in ovariectomized sheep. A bone histomorphometric study. Vet Comp Orthop Traumatol 20: 18-23.

Koyama H, Nakade O, Takada Y, Kaku T, Lau KH (2002) Melatonin at pharmacologic doses increases bone mass by suppressing resorption through down-regulation of the RANKL-mediated osteoclast formation and activation. J Bone Miner Res 17: 1219-1229.

Krolner B (1983) Seasonal variation of lumbar spine bone mineral content in normal women. Calcif Tissue Int 35: 145-147.

Lill CA, Fluegel AK, Schneider E (2002) Effect of ovariectomy, malnutrition and glucocorticoid application on bone properties in sheep: a pilot study. Osteoporos Int 13: 480-486.

Liu YF, Manjubala I, Schell H, Epari DR, Roschger P, Duda GN, Fratzl P (2010) Size and habit of mineral particles in bone and mineralized callus during bone healing in sheep. J Bone Miner Res 25: 2029-2038.

MacLeay JM, Olson JD, Enns RM, Les CM, Toth CA, Wheeler DL, Turner AS (2004a) Dietary-induced metabolic acidosis decreases bone mineral density in mature ovariectomized ewes. Calcif Tissue Int 75: 431437.

MacLeay JM, Olson JD, Turner AS (2004b) Effect of dietary-induced metabolic acidosis and ovariectomy on bone mineral density and markers of bone turnover. J Bone Miner Metab 22: 561-568.

Mahmood I, Martinez M, Hunter RP (2006) Interspecies allometric scaling. Part I: prediction of clearance in large animals. J Vet Pharmacol Ther 29: 415-423.

Manjubala I, Liu Y, Epari DR, Roschger P, Schell H, Fratzl P, Duda GN (2009) Spatial and temporal variations of mechanical properties and mineral content of the external callus during bone healing. Bone 45: 185-192.

Martin A, de Vittoris R, David V, Moraes R, Begeot M, Lafage-Proust MH, Alexandre C, Vico L, Thomas T (2005) Leptin modulates both resorption and formation while preventing disuse-induced bone loss in tail-suspended female rats. Endocrinology 146: 3652-3659.

Mathey J, Horcajada-Molteni MN, Chanteranne B, Picherit C, Puel C, Lebecque P, Cubizoles C, Davicco MJ, Coxam V, Barlet JP (2002) Bone mass in obese diabetic Zucker rats: influence of treadmill running. Calcif Tissue Int 70: 305-311.

Melton L Jr (2003) Epidemiology worldwide. Endocrinol Metab Clin North Am 32: 1-13.

Mori R, Kodaka T, Soeta S, Sato J, Kakino J, Hamato S, Takaki H, Naito Y (2005) Preliminary study of histological comparison on the growth patterns of long-bone cortex in young calf, pig, and sheep. J Vet Med Sci 67: 1223-1229.

Mori R, Hirayama A, Kodaka T, Nakamura M (2007) Histological and physicochemical studies of hypercalcified 
primear lines in the laminar bone of young calves. Anat Sci Int 82: 108-115.

Newman E, Turner AS, Wark JD (1995) The potential of sheep for the study of osteopenia: current status and comparison with other animal models. Bone 16: 277S-284S.

Newton BI, Cooper RC, Gilbert JA, Johnson RB, Zardiackas LD (2004) The ovariectomized sheep as a model for human bone loss. J Comp Pathol 130: 323-326.

O'Connell SL 1999 The sheep as an experimental model for osteoporosis. PhD Thesis, Department of Medicine, University of Melbourne, Melbourne, Australia.

Oheim R, Beil FT, Barvencik F, Egermann M, Amling M, Clarke IJ, Pogoda P (2012) Targeting the lateral but not the third ventricle induces bone loss in ewe: An experimental approach to generate an improved large animal model of osteoporosis. J Trauma Acute Care Surg 72: 720-726.

Pastoureau P, Merle B, Delmas PD (1988) Specific radioimmunoassay for ovine bone gla-protein (osteocalcin). Acta Endocrinol 119: 152-160.

Pastoureau P, Meunier PJ, Delmas PD (1991) Serum osteocalcin (bone Gla-protein), an index of bone growth in lambs. Comparison with age-related histomorphometric changes. Bone 12: 143-149.

Pearce AI, Richards RG, Milz S, Schneider E, Pearce SG (2007) Animal models for implant biomaterial research in bone: a review. Eur Cell Mater 13: 1-10.

Pogoda P, Egermann M, Schnell JC, Priemel M, Schilling AF, Alini M, Schinke T, Rueger JM, Schneider E, Clarke I, Amling M (2006) Leptin inhibits bone formation not only in rodents, but also in sheep. J Bone Miner Res 21: 1591-1599.

Radio NM, Doctor JS, Witt-Enderby PA (2006) Melatonin enhances alkaline phosphatase activity in differentiating human adult mesenchymal stem cells grown in osteogenic medium via MT2 melatonin receptors and the MEK/ERK (1/2) signaling cascade. J Pineal Res 40: 332-342.

Reinwald S, Burr D (2008) Review of nonprimate, large animal models for osteoporosis research. J Bone Miner Res 23: 1353-1368.

Riggs BL, Melton L Jr (1986) Involutional osteoporosis. N Engl J Med 314: 1676-1686.

Rocca M, Fini M, Giavaresi G, Aldini NN, Giardino R (2002) Osteointegration of hydroxyapatite-coated and uncoated titanium screws in long-term ovariectomized sheep. Biomaterials 23: 1017-1023.

Rosen CJ, Morrison A, Zhou H, Storm D, Hunter SJ, Musgrave K, Chen T, Wei W, Holick MF (1994) Elderly women in northern New England exhibit seasonal changes in bone mineral density and calciotropic hormones. Bone Miner 25: 83-92.

Ross PD (1996) Osteoporosis. Frequency, consequences, and risk factors. Arch Intern Med 156: 1399-1411.

Roth JA, Kim BG, Lin WL, Cho MI (1999) Melatonin promotes osteoblast differentiation and bone formation. J Biol Chem 274: 22041-22047.

Schorlemmer S, Gohl C, Iwabu S, Ignatius A, Claes L, Augat P (2003) Glucocorticoid treatment of ovariectomized sheep affects mineral density, structure, and mechanical properties of cancellous bone. J Bone Miner Res 18: 20102015.

Shapiro F (2008) Bone development and its relation to fracture repair: the role of mesenchymal osteoblasts and surface osteoblasts. Eur Cell Mater 15: 53-76.

Shapiro IM, Hickok NJ, Parvizi J, Stewart S, Schaer TP (2012) Molecular engineering of an orthopaedic implant: from bench to bedside. Eur Cell Mater 23: 362-370.

Sigrist IM, Gerhardt C, Alini M, Schneider E, Egermann M (2007) The long-term effects of ovariectomy on bone metabolism in sheep. J Bone Miner Metab 25: 28-35.

Skerry TM, Lanyon LE (1995) Interruption of disuse by short duration walking exercise does not prevent bone loss in the sheep calcaneus. Bone 16: 269-274.

Sone K, Yamamoto-Sawamura T, Kuwahara S, Nishijima K, Ohno T, Aoyama H, Tanaka S (2007) Changes of estrous cycles with aging in female F344/n rats. Exp Anim 56: 139-148.

Stadelmann VA, Gauthier O, Terrier A, Bouler JM, Pioletti DP (2008) Implants delivering bisphosphonate locally increase periprosthetic bone density in an osteoporotic sheep model. A pilot study. Eur Cell Mater 16: $10-16$.

Tamasi JA, Arey BJ, Bertolini DR, Feyen JH (2003) Characterization of bone structure in leptin receptordeficient Zucker (fa/fa) rats. J Bone Miner Res 18: 1605 1611.

Thomas T (2003) Leptin: a potential mediator for protective effects of fat mass on bone tissue. Joint Bone Spine 70: 18-21.

Thomas T, Skerry TM, Vico L, Caulin F, Lanyon LE, Alexandre C (1995) Ineffectiveness of calcitonin on a local-disuse osteoporosis in the sheep: a histomorphometric study. Calcif Tissue Int 57: 224-228.

Thomas KA, Toth JM, Crawford NR, Seim III HB, Shi LL, Harris MB, Turner AS (2008) Bioresorbable polylactide interbody implants in an ovine anterior cervical discectomy and fusion model: three-year results. Spine 33: 734-742.

Thompson DD, Simmons HA, Pirie CM, Ke HZ (1995) FDA Guidelines and animal models for osteoporosis. Bone 17: $125 \mathrm{~S}-133 \mathrm{~S}$.

Turner AS (2002) The sheep as a model for osteoporosis in humans. Vet J 163: 232-239.

Turner AS, Alvis M, Myers W, Stevens ML, Lundy MW (1995) Changes in bone mineral density and bone-specific alkaline phosphatase in ovariectomized ewes. Bone 17: 395S-402S.

Veigel E, Moore RJ, Zarrinkalam MR, Schulze D, Sauerbier S, Schmelzeisen R, Voss PJ (2011) Osteopenia in the maxillofacial area: a study in sheep. Osteoporos Int 22: 1115-1121.

Verron E, Gauthier O, Janvier P, Pilet P, Lesoeur $\mathrm{J}$, Bujoli B, Guicheux J, Bouler JM (2010) In vivo bone augmentation in an osteoporotic environment using bisphosphonate-loaded calcium deficient apatite. Biomaterials 31: 7776-7784.

Wilke HJ, Kettler A, Wenger KH, Claes LE (1997) Anatomy of the sheep spine and its comparison to the human spine. Anat Rec 247: 542-555. 
Witt F, Petersen A, Seidel R, Vetter A, Weinkamer $\mathrm{R}$, Duda GN (2011) Combined in vivo/in silico study of mechanobiological mechanisms during endochondral ossification in bone healing. Ann Biomed Eng 39: 25312541.

Zarrinkalam MR, Mulaibrahimovic A, Atkins GJ, Moore RJ (2012) Changes in osteocyte density correspond with changes in osteoblast and osteoclast activity in an osteoporotic sheep model. Osteoporos Int 23: 1329-1336.

\section{Discussion with Reviewers}

Reviewer I: As stated in the paper, the sheep model cannot mimic the human postmenopausal osteoporotic situation by $100 \%$. How reliably can results from sheep studies with induction of osteoporosis by interventions on the central regulatory mechanics be transferred to the human situation? Should they mainly be used for development of new implants or are they also of relevance for antiosteoporotic medication?

Authors: Every model mirrors only certain aspects of the disease it should represent. This is also true when it comes to sheep models of osteoporosis and how they compare to patients suffering from postmenopausal osteoporosis. Nevertheless, these models should definitely be valuable for studying new implants and/or bone substitutes due their significant and reliable bone loss. Furthermore, it is quite conceivable that certain anti-osteoporotic drugs might be tested in these models.

Reviewer IV: 1. What are the potential or proven disadvantages of interfering with central regulation of bone metabolism, in particular what other effects can be seen? 2. How do the effects of centrally (surgically) induced osteoporosis compare with changes observed in women during transition from reproductive age into menopause? Authors: Sheep models of centrally induced bone loss are doubtless very complex systems, and as recommended for all animal models, thorough characterisation of the model is of crucial importance. The HPD model, for example, seems attractive to study effects of anti-osteoporotic drugs in a pronounced low-turnover situation, as clinically often seen in senile osteoporosis, in contrast to the high-turnover situation typically found in patients suffering from early postmenopausal osteoporosis. 